\title{
Relatório Anual de Gestão - 2009
}

Ricardo P. Câmara Leal

Editor, Revista Brasileira de Finanças

\section{Resumo}

O conteúdo da Revista permaneceu on-line e aberto e também foi mantida a revista impressa, graças ao auxílio do $\mathrm{CNPq} /$ Capes. Entre as principais ações de 2009 estão o aumento no número de fascículos por ano de 3 para 4, permitindo a publicação de pelo menos 20 artigos por ano. O cronograma de publicação da RBFin encontra-se rigorosamente em dia. A revista é indexada no EconLit, Google Scholar, Ebsco e Gale e listada nos diretórios JEL, Latindex e Cabell's. A RBFin foi enquadrada como B1 na área de Administração do Qualis/Capes. O Corpo Editorial Científico é parcialmente renovado a cada ano e é formado por 18 membros provenientes de cinco países, sendo dez provenientes de seis diferentes estados do Brasil. A taxa de aceitação foi de $41 \%$ para os artigos enviados em 2008 e de $26,5 \%$ para os enviados em 2009. A média de dias entre o recebimento e a aceitação para os artigos publicados em 2009 foi de 210 . O pior caso foi de 552 dias. A média de dias entre o recebimento e a publicação foi de 352 . O pior caso foi de 641 dias. A média de acessos por artigo até janeiro de 2010 foi 750. Oitenta e sete indivíduos atuaram como avaliadores em 2009.

\begin{abstract}
The contents of the Journal remained open and online and its printed version has been maintained. Among the main actions in 2009 are the increase in the number of issues per year from 3 to 4 , allowing the publication of at least 20 articles per year. The schedule from publication of RBFin is strictly up to date. The journal is indexed in EconLit, Google Scholar, Ebsco and Gale and listed in the JEL, Latindex and Cabell's directories. The Editorial Board is partially renewed each year and consists of 18 members from five countries. The acceptance rate was $41 \%$ for the articles received in 2008 and $26.5 \%$ for those received in 2009 . The average number of days between reception and acceptance for articles published in 2009 was 210 . The worst case was 552 days. The average number of days between reception and publication was 352 . The worst case was 641 days. The average of hits per article until January 2010 was 750 . Eighty-seven individuals have served as reviewers in 2009.
\end{abstract}




\section{Introdução}

Este relatório apresenta os principais aspectos do desenvolvimento da RBFin em 2009, bem como algumas de suas estatísticas editoriais e de distribuição. O número de artigos enviados no ano foi o maior da história da Revista. A RBFin manteve sua interface na Internet para o envio e avaliação de artigos com todo o seu conteúdo com acesso gratuito, aumentou o número de fascículos publicados para quatro por ano, deu continuidade ao processo permanente de renovação do Corpo Editorial Científico, passou a ser indexada no Ebsco e Gale e solicitou sua inclusão no Scielo, ainda sem resposta, entre outras ações. Espera-se que todos os avanços levem a melhorias significativas do processo editorial e da qualidade da RBFin. A RBFin contou com o apoio do CNPq/Capes no ano.

\section{Avanços em 2009}

Entre as principais ações de 2009 estão o aumento no número de fascículos por ano de três para quatro, permitindo a publicação de pelo menos 20 artigos por ano. O cronograma de publicação da RBFin encontra-se rigorosamente em dia. Houve continuidade do processo de renovação permanente do Corpo Editorial Científico, detalhada adiante. O conteúdo da Revista permaneceu on-line e aberto e também foi mantida a revista impressa, graças ao auxílio do CNPq/Capes. O processo de envio e avaliação de artigos é feito exclusivamente on-line por meio do sistema Open Journals System (OJS). O OJS permite que toda a correspondência e versões dos artigos seja armazenada no sistema. Tudo passou a ser guardado nos servidores da FGV/RJ automaticamente e a estar sujeito aos procedimentos de segurança e preservação de dados da FGV/RJ. O OJS permite que se entrem com muitas informações sobre os artigos, os metadados, tais como título, resumo, palavras chave e códigos de indexação JEL, que podem ser integradas com os sistemas de difusão de periódicos acadêmicos que empregam a tecnologia Open Archives Initiative. Isso permitirá que os autores tenham divulgação mais ampla de seus artigos.

Com a abertura de todo o conteúdo na Internet, foi possível integrar a Revista ao Google Scholar. A revista já era indexada no EconLit e no Google Scholar e listada nos diretórios JEL, Latindex e Cabell's. Em 2009, a revista foi incluída nos indexadores Gale e Ebsco e solicitamos nossa inclusão no Scopos e Scielo, e no Directory of Open Access Journals (DOAJ), ainda sem resposta. Estamos também analisando o ingresso da revista no programa Partners in Publishing da Social Sciences Research Network (ssrn.com), onde há custo, de forma a atrair mais artigos do exterior. No futuro próximo procuraremos incluir a revista na Repec e na Redalyc (Red de Revistas Científicas de América Latina y el Caribe, España y Portugal). 
Durante o ano a secretaria editorial da revista passou a ser acumulada pelo editor com a saída de Rose Amandula, que serviu à revista nos últimos anos. Nossos agradecimentos à Rose pela contribuição à RBFin. Algumas mudanças de formatação e informações foram incluídas na Revista e no website visando a pontuação máxima possível na Capes. Contatos foram feitos no âmbito do comitê de avaliação da Capes na área de economia visando obter informações e esclarecimentos para que a Revista concorra à melhor avaliação possível nesta área. $\mathrm{Na}$ nova escala da Capes, a RBFin foi enquadrada como B1 na área de Administração e Ciências Contábeis e B3 em Economia. Esperamos que com o futuro ingresso da RBFin no indexador Scielo ou Scopus passemos a ter uma classificação ainda melhor nas duas áreas.

\section{Prêmio SBFin de Melhor Artigo}

No Encontro Brasileiro de Finanças, em julho de 2009, foi entregue o Prêmio SBFin de melhor artigo publicado na Revista em 2008 (volume 6). O artigo vencedor do prêmio de R 10 mil reais foi "Excesso de Confiança, Otimismo Gerencial e os Determinantes da Estrutura de Capital" de Lucas Ayres B. de C. Barros (Universidade Presbiteriana Mackenzie) e Alexandre Di Miceli da Silveira (FEA/USP). Foram concedidas menções honrosas aos artigos "Transmissão Financeira entre o Mercado Acionário e o Mercado de Títulos de Dívida" de Francisco Eduardo de Luna e Almeida Santos (Banco Central) e "A Influência das Redes de Relações Corporativas no Desempenho das Empresas do Novo Mercado" de Wesley Mendes da Silva (Universidade Presbiteriana Mackenzie), Luciano Rossoni (Universidade Positivo), Diógenes Leiva Martin (Universidade Presbiteriana Mackenzie) e Roy Martelanc (FEA/USP). O prêmio SBFin é agraciado ao artigo mais votado pelo comitê formado pelo editor e pelos quatro editores associados.

\section{Corpo Editorial Científico}

Todos os membros do Corpo Editorial Científico (CEC) têm mandatos renováveis de três anos a partir da data de seu ingresso neste órgão, além do compromisso de avaliarem até dois artigos por ano e colaborarem no processo de indicação de avaliadores. Dos 18 membros do CEC ao final de 2009, 3 tinham concluído seus mandatos, 8 têm mandatos que vencem ao final de 2010 e 7 têm mandatos que vencem ao final de 2011. A renovação permanente do CEC visa manter um corpo engajado com o processo editorial com não mais do que 18 membros e com diversificação regional e internacional. Para 2010 não haverá alteração no total de membros e na sua diversificação regional e internacional.

A partir de 2009 passaram a integrar o CEC: Alexandre di Miceli da Silveira (USP), Ana Paula Serra (Universidade do Porto), Heitor de Almeida (reconduzido, University of Illinois), Marcelo Fernandes (Queen Mary University), Márcio Nakane (USP), Pedro Saffi (IESE, Universidad de Navarra) e Rodrigo de 
Losso da Silveira Bueno (USP). Para os mandatos de 2010 a 2012 foram reconduzidos Daniel Ferreira (London School of Economics and Political Science) e Murillo Campello (University of Illinois). Rodrigo Verdi (MIT) passou a integrar o CEC no lugar de Armando Gomes (Washington University in Saint Louis).

\begin{tabular}{ccc}
\multicolumn{3}{c}{ Tabela 1: Estatísticas sobre o Corpo Editorial Científico } \\
\hline País e Estado & Ao final de 2008 & A partir de 2009 \\
\hline Brasil & 10 & 10 \\
$S P$ & 4 & 4 \\
$R J$ & 2 & 2 \\
$D F$ & 1 & 1 \\
$E S$ & 1 & 1 \\
$M G$ & 1 & 1 \\
$R S$ & 1 & 1 \\
EUA & 3 & 3 \\
Portugal & 2 & 2 \\
Reino Unido & 2 & 2 \\
Espanha & 1 & 1 \\
\hline Total & 18 & 18 \\
\hline
\end{tabular}

\section{Comitê de Política Editorial}

O comitê é formado atualmente pelo Presidente da Sociedade Brasileira de Finanças (SBFin) (Richard Saito), pelos Diretores de Publicação da SBFin (Márcio Garcia e Paulo Terra) e pelo Editor da RBFin (Ricardo P. C. Leal). O comitê tem a função de tomar as principais decisões sobre a Revista, tais como sua forma e frequência de publicação, a composição do Corpo Editorial Científico, a definição de números especiais e das diversas políticas pertinentes à Revista. As sugestões do comitê são submetidas ao Conselho Diretor da Sociedade Brasileira de Finanças, mantenedora da Revista.

\section{Estatísticas Editoriais}

O quantitativo de processamento de artigos da RBFin em 31 de dezembro de 2009 encontra-se na Tabela 2. A taxa de aceitação da revista em relação ao total de artigos com decisão definitiva (aceitos, recusados e retirados) estava em 26,5\% para o ano de 2009. Esta taxa provavelmente vai aumentar quando todos os artigos que ainda estão no processo de avaliação obtiverem uma decisão definitiva, uma vez que muitos dos artigos são rejeitados diretamente pelos editores sem serem submetidos a avaliadores. A taxa de aceitação para os artigos enviados em 2008 foi de $41 \%$. Para os artigos publicados em 2009, volume 7, números 1, 2, 3 e 4, a média de dias entre o recebimento e a aceitação foi de 210 . O pior caso foi de 552 dias. A média de dias entre o recebimento e a publicação foi de 352 . O pior caso 
foi de 641 dias. Os tempos médios de 2009 foram menores que as de 2008. Em 2009 foram publicados 20 artigos.

\section{Distribuição e Acesso à Revista}

Desde a abertura do conteúdo da RBFin na Internet em julho de 2008 o total de acessos foi de 63.768 para os 85 artigos disponíveis, levando a uma média de 750 acessos por artigo. Do total de acessos, $15 \%$ são feitos pela versão em inglês do sítio. Este levantamento foi feito nos dias 14 e 23 de janeiro de 2010.

A RBFin impressa é distribuída a seus assinantes, em geral membros da Sociedade Brasileira de Finanças, e oferecida gratuitamente para diversas bibliotecas e programas de pós-graduação na área de Administração. A Revista é distribuída a todos os inscritos no Encontro Brasileiro de Finanças e cada autor recebe três exemplares do fascículo em que seu artigo foi publicado. O quantitativo de distribuição da Revista encontra-se na Tabela 3.

Tabela 2: Estatísticas Editoriais dos Artigos Recebidos ao final de Dezembro de 2009

\begin{tabular}{lc}
\hline & 2009 \\
\hline Artigos recebidos & 83 \\
Artigos recebidos e aceitos & 9 \\
Artigos recebidos e recusados & 51 \\
Artigos recebidos e retirados pelos autores & 1 \\
Artigos recebidos em avaliação & 10 \\
Artigos recebidos com autores para revisão & 11 \\
Artigos publicados & 20 \\
Artigos em avaliação de anos anteriores & 1 \\
Artigos com autores para revisão de anos anteriores & 0 \\
Artigos aceitos e ainda não publicados, todos os anos & 5 \\
Estoque (em avaliação, revisão e aceitos não publicados) & 27 \\
\hline
\end{tabular}

Tabela 3: Quantitativo da Distribuição da RBFin Impressa (Volume 7, Número 4, 2009)

\begin{tabular}{lc}
\hline Assinaturas e membros da SBFin & 157 \\
Envio gratuito a bibliotecas nacionais & 57 \\
Envio gratuito a bibliotecas no exterior & 6 \\
Permutas & 0 \\
\hline Total & 220 \\
\hline
\end{tabular}




\section{Nominata dos Consultores Ad-Hoc (Avaliadores)}

O desenvolvimento de uma revista de qualidade passa pelo engajamento de acadêmicos de alta qualificação no processo de avaliação dos artigos. Os editores da RBFin agradecem aos 87 indivíduos abaixo que prestaram este serviço voluntário para os artigos com avaliação concluída em 2009. A política da revista é que cada avaliador não faça mais do que uma avaliação por ano, exceto avaliações subsequentes do mesmo artigo.

Adrian Pizzinga, DEE/PUC-Rio

Alexandre di Micelli da Silveira (2 artigos), FEA/USP

Alexandre Lowenkron, Banco BBM

Andrea Minardi, Insper

Antônio Carlos Figueiredo, IAG/PUC-Rio

Antônio Gledson de Carvalho, EAESP/FGV

Antonio Zorato Sanvicente (2 artigos), Insper

Aureliano Angel Bressan, FACE/UFMG

Beatriz Mendes, IM/UFRJ

Benjamin Tabak, Banco Central e UCB

Caio Almeida, EPGE/FGV

Celso Lemme, Coppead/UFRJ

Cesar Cupertino, Polícia Federal, SC

Charles Carmona, DCA/UFPE

Christian Zimmer, Banco Itaú

Claudio Barbedo (2 artigos), Banco Central e Ibmec/RJ

Cláudio Cunha, Economia, PUC-Rio

Diógenes Manoel Leiva Martin, Universidade Presbiteriana Mackenzie

Eduardo Facó Lemgruber, Coppead/UFRJ

Eduardo Kayo, Universidade Presbiteriana Mackenzie

Eduardo Saliby, Coppead/UFRJ

Erik Figueirêdo, UFPB

Fábia de Carvalho, Banco Central

Fabiano Guasti Lima, FEARP/USP

Fábio Araújo, Banco Central

Fábio Frezatti, FEA/USP

Fernanda Perobelli, FEA/UFJF

Fernando Aiube, Petrobras e DEI/PUC-Rio

Fernando Galdi, Fucape

Fernando Seabra, UFSC

Flávio Ziegelmann , UFRGS

Francisco David Giovanni Vieira, UEM

George Ohanian, EAESP/FGV

Helder Parra Palaro, City University, UK

Hsia Hua Sheng, EAESP/FGV 
Jairo Procianoy (2 artigos), EA/UFRGS

Jaqueline Marins, Banco Central

João Carlos Douat, EAESP/FGV

João Leitão, Universidade Técnica de Lisboa

João Victor Issler, EPGE/FGV

João Zani, Unisinos

Joel Correa da Rosa, UFF

John O'Hanlon, Lancaster University

José Fajardo Barbachan, Ibmec/RJ

José Francisco de Carvalho Rezende, MCC/FAF/UERJ

José Luiz Fernandes, Banco Central

José Renato Haas Ornelas, Banco Central

José Roberto Savóia, FEA/USP

José Vicente, Banco Central

Julia von Maltzan Pacheco, EESP/FGV

Lucas Ayres, Universidade Presbiteriana Mackenzie

Luis Eduardo Brandão, IAG/PUC-Rio

Luis Paulo Lopes Fávero, FEA/USP

Luiz Antonio da Rocha Dib, Coppead/UFRJ

Luiz Felipe Jacques da Motta, IAG/PUC-Rio

Marcelo Fernandes, Queen Mary University of London

Marcelo Mello (2 artigos), Ibmec/RJ

Marcelo Nagano, USP São Carlos

Marcelo Portugal, UFRGS

Márcio Holland, EESP/FGV

Marcos Eugênio Silva, FEA/USP

Maurício Simiano Nunes, UFRGS

Mauro Rincon, DCC/UFRJ

Myrian Neves, Banco Central

Nelson Tanaka, IME/USP

Newton Costa Jr, UFSC

Paulo Terra, UFRGS

Pedro Valls Pereira, EESP/FGV

Rafael Schiozer, EAESP/FGV

Reinaldo Guerreiro, FEA/USP

Ricardo Bordeaux Rego, UFF

Ricardo Dias de Oliveira Brito, Insper

Ricardo Leal (4 artigos), Coppead/UFRJ

Richard Saito, EAESP/FGV

Roberto Decourt, UFRGS

Roberto Meurer, UFSC

Rodrigo de Losso, FEA/USP

Rodrigo Verdi, MIT

Rogério Rosenfeld , UNESP 
Rosilene Marcon, Univali

Sandro Canesso de Andrade, University of Miami

Sergio Jurandyr Machado, Insper

Tomás de Aquino Guimarães, UNB

Vicente Pacheco, UFPR

Walter Lee Ness, IAG/PUC-Rio

William Eid Jr, EAESP/FGV

Wilson Nakamura, Universidade Presbiteriana Mackenzie

Rio de Janeiro, 28 de janeiro de 2010. 